\title{
A Proposal to Implement Mobile Wireless IP Telephony to the Mekong River Region
}

\author{
Yuji Hatakeyama \\ NTTDoCoMo \\ Chiyoda-ku, Tokyo 100-6150 \\ hatakeyamay@nttdocomo.co.jp

\section{Hideya Otani \\ B eMap} \\ ootani@bemap.co.jp \\ Kenichi Takeshita \\ NTTBP, \\ Chiyoda-ku, Tokyo 101-8413 \\ takesita@ntt-bp.com

\section{Akiyuki Goto \\ NECTEC, Thailand \\ akiyuki.goto@nectec.or.th}

\section{Summary}

With the development of wireless LAN and VoIP technology, economical build-up of infrastructure in the rural areas of developing countries is now emerge in as a real possibility. In this milieu, we conducted an experiment at Thai National Mae Fah Luang University (MFLU) located in the outskirts of Chiang Rai in Northern Thailand, in collaboration with Thai Electronics and Computer Technology Center (NECTEC), where we verified the viability of mobile wireless IP telephony and WIPAS (Wireless IP Access System) developed by NTT .

This paper reports on the demonstration experiment of FWA (Fixed Wireless Access), and in addition, based on its results, examines the means of aligning WIPAS, wireless IP telephony and cellular network, and proposes the adoption of mobile wireless IP telephony in the rural areas of developing countries, which provides the mobility with the application of FMC (Fixed Mobile Convergence).

\section{Introduction}

"Missing Link" which was reported by the independent committee of the International Telecommunications Union (ITU) in 1984 pointed out the disparity between developed and developing countries, as well as between urban and rural areas within the developing countries in terms of the level of telecommunication available. However, at present the disparity between urban and rural areas of the developing countries is more of an issue, rather than between developed and developing countries. This is due to the fact that build-up of access systems requires a tremendous amount of investment, and its cost is hampering the penetration of telephone in the developing countries, particularly in rural areas where the population is more dispersed. In response, ITU World Telecommunications Forum in 2001 adopted a resolution calling for "promotion of IP telephony," as it enables the developing countries to build low-cost telephone network. Fixed line IP telephony has actually been introduced in the rural areas of some developing countries. Meanwhile, in the developed countries, IP telephony system with wireless LAN and portable wireless IP telephone terminal is beginning be introduced commercially for enterprises. In this context, we conducted verification tests for mobile wireless IP telephony in the so-called Golden Triangle are in the northern Thailand ${ }^{[1] \sim[4]}$.
Hirofumi Ichikawa NTTAT

Totsuka-ku, Yokohama city 244-0805

Hirofumi.Ichikawa@ntt-at.co.jp

Thongchai Yooyativong

ae Fah Luang Univ., Thailand

uang, Chiang Rai 57100 Thailand

thongchai@mfu.ac.th

\author{
Yukio Yokoi \\ NaganoJRC \\ Inasato-cho, Nagano city, 381-2288 \\ yyokoi@njrc.co.jp \\ Mitsuji Matsumoto \\ GITS, Waseda Univ. \\ Honjo city, 367-0035 \\ mmatsumoto@waseda.jp
}

In this paper, we have reviewed the viability of FWA technology with IEEE802.11b (hereinafter "Wi-Fi"; name adopted by the certification organization) and wireless broadband access system, as well as mobile centrex and FMC technologies as a means to connect to PLMN (Public Land Mobile Network) and PSTN (Public Switched Telephone Network) in the rural areas in developing countries, such the Mekong River region. As a result we are proposing a rural telecommunication system with mobile wireless IP telephony, which allows for mobility equal to cellular phone and enables the use of various application services on the Internet, rather than just being a substitute for fixed telephony.

\section{Rural Telecommunications Networks Today}

\subsection{Disparity between urban and rural areas}

Many of the capital and major cities of the developing countries now have cellular phones, international telecommunication and Internet available. However, in rural areas, many are without the benefit of cellular phone or fixed line telephone, let alone the Internet. The central issue is shifting from disparity between developed and developing countries to between urban and rural areas of within developing countries. When compared with Japan, the availability of telephone service within developing countries is more concentrated in urban areas. In Vietnam, for instance, Hanoi and Ho Chi Minh account for $10 \%$ of the population, but $40 \%$ of the telephone subscribers is concentrated in these two cities. As shown in fig.1, the population in rural areas is much larger ${ }^{[5]}$. Particularly, in Mekong basin countries which has close relationships with Japan through ODA (Official Development Aid), clearly there are more people living in the rural areas. Providing telecommunication services to rural areas is an urgent task.

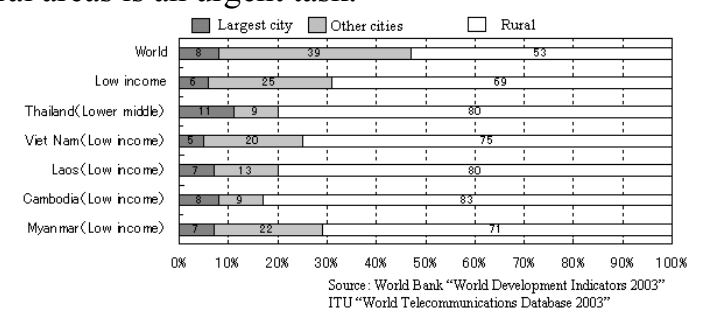

Figure 1 Ratio of rural population in Mekong Basin countries

2.2 Access network

In the afore-mentioned ITU "Missing Link" report 20 years ago, it was pointed out that there was no viable telecommunication technology for remote, sparsely 
populated areas, where the cost of subscriber line was 10 times higher than urban areas, accounting for $80 \%$ of the total cost as opposed to $40 \%$. Reduction of the cost of building access network in rural areas is still an important issue today ${ }^{[6]}$. Multiplex transmission over fixed metallic subscriber line, fiber optic subscriber line, wireless MAS (Multi-channel Access System), VSAT (Very Small Aperture Terminal) and LEO (Low Earth Orbit) systems were implemented, but due to cost and operability issues, their uptake was limited. On the other hand, cellular phone which provides mobility, Internet access and mail capability, has now become available worldwide, bringing down the cost and gradually penetrating not only urban but rural areas of developing countries as well. In addition, there have been attempts to use fixed-type IP telephone with wireless LAN in rural areas conducted in Laos, Bhutan and other countries ${ }^{[7]},{ }^{[8]}$. In Thailand, NECTEC implemented a wireless IP system called Rural Wireless Broadband Access (RWBA), specifically designed for rural areas ${ }^{[9]}$.

2.3 Current status and characteristics in the region

Many of the developing countries in Asia-Pacific region are trying to build up their telecommunication infrastructures through ODA from Japan and other means. The current telecommunication service environment is indicated in Table 1. Construction of their telecommunication infrastructures also requires consideration of various factors listed in Table 2 .

Table 1 Penetration ratio of services in the region

\begin{tabular}{|c||c|c|c|}
\hline Country & $\begin{array}{c}\text { Cellular } \\
\text { phone }\end{array}$ & $\begin{array}{c}\text { Fixed } \\
\text { telephone }\end{array}$ & Internet \\
\hline \hline Thailand & 45.36 & 10.55 & 9.64 \\
\hline Vietnam & 7.28 & 5.41 & 4.03 \\
\hline Laos & 6.39 & 1.12 & 0.26 \\
\hline Cambodia & 7.66 & 0.26 & 0.06 \\
\hline Myanmar & 0.20 & 0.72 & 0.25 \\
\hline
\end{tabular}

(Penetration Ratio: Subscribers per 100 people)

Source: Cellular phone June2005 World Cellular Information service

Fixed telephone Dec.2003 ITU"World Telecommunication Indicators Database2004"

Table 2 Characteristics of Mekong Basin

\begin{tabular}{|l|l|}
\hline \multicolumn{1}{|c|}{ Category } & \multicolumn{1}{c|}{ Comment } \\
\hline \hline $\begin{array}{l}\text { Service } \\
\text { availability }\end{array}$ & $\begin{array}{l}\text { - Cellular phone (GSM) more available than fixed telephone. } \\
\text { Those in rural areas without phones are also aware of its } \\
\text { convenience } \\
\text { Many villages have no or only several telephone lines }\end{array}$ \\
\hline $\begin{array}{l}\text { Infrastruc } \\
\text { ture }\end{array}$ & $\begin{array}{l}\text { - Basic infrastructure is in place to a certain degree - optical } \\
\text { fiber is connected to the county capital or center of villages } \\
\text { - Last one mile is an issue in rural areas } \\
\text { Some villages are without power } \\
\text { (ex. Thailand: 97\%, Vietnam: 65\%) }\end{array}$ \\
\hline $\begin{array}{l}\text { Policy and } \\
\text { regulations }\end{array}$ & $\begin{array}{l}\text { Trying to realize broadband environment with internet } \\
\text { access in schools or community halls } \\
\text { Many countries restrict VoIP service }\end{array}$ \\
\hline $\begin{array}{l}\text { Environ } \\
\text { ment }\end{array}$ & $\begin{array}{l}\text { - No high structures - line of sight easy to obtain } \\
\text { Squalls in rainy season (Instantaneous over 100mm/hour) }\end{array}$ \\
\hline
\end{tabular}

\section{Demonstrating Viability of FWA}

\subsection{Configuration of demonstration}

Demonstration experiment was conducted in the facilities inside MFLU as shown in Fig. 2, and the operability of mobile wireless IP phone system in the campus was verified. 16 access points were set up, focusing on the areas where high traffic was anticipated, such as educational affairs department counter, dining hall and meeting rooms. Internal LAN is a 100BASE-FX with optical fiber. MFLU is connected to the inter-university network in Thailand (UniNET) and academic network (ThaiSARN) through optical fiber. In the experiment, we asked for volunteer monitors from faculty, staff and students, and provided them with 75 mobile IP phone terminals, and it was conducted for four months from October 2004.

Also, in order to verify some effective means of expanding the system to adjacent areas, an elementary school about 2.3 kilometers away was included, using WIPAS, a high-speed broadband wireless system developed by NTT and introduced in Japan as entrance circuit. Specifications of WIPAS are shown in Table 3. Same access point as the university was set up in the school, enabling the use of internal phone call with the university through wireless IP telephone. In addition, the computers connected to the phone line were linked to the university LAN via WIPAS, enabling comfortable Internet environment. A web camera was set up in the elementary school, enabling remote monitoring of the location of WIPAS.

For power supply, a combined unit of solar and lead-free, long-lasting and safe LiMn batteries was installed, and its operation under the local weather condition was verified

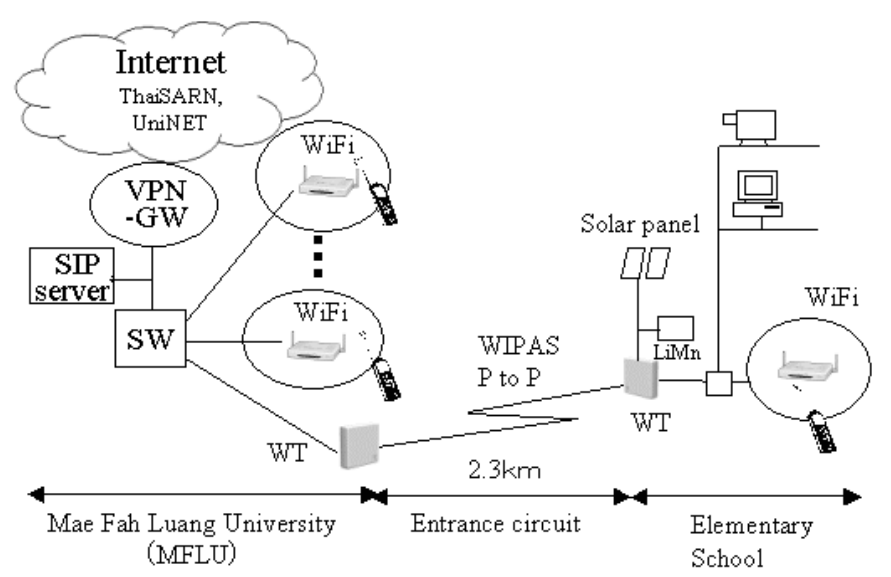

Figure 2 Network configuration of the demonstration

Table 3 Main specifications of WIPAS

\begin{tabular}{|c|c|c|}
\hline Items & Specifications & Field test in MFLU \\
\hline Frequency & $26 \mathrm{GHz}$ band & $26 \mathrm{GHz}$ band \\
\hline Transmission & TDMA/TDD & TDD \\
\hline \multirow{2}{*}{$\begin{array}{l}\text { Transmission } \\
\text { Capacity, } \\
\text { Modulation }\end{array}$} & $40 \mathrm{Mbit} / \mathrm{s}$ (QPSK), $80 \mathrm{Mbit} / \mathrm{s}(16 \mathrm{QAM})$ & $80 \mathrm{Mbit} / \mathrm{s} 16 \mathrm{QAM}$ \\
\hline & $\begin{array}{l}\text { Ethernet } \\
23 \mathrm{Mbit} / \mathrm{s} \text { (QPSK), } 46 \mathrm{Mbit} / \mathrm{s}(16 \mathrm{QAM})\end{array}$ & $\begin{array}{c}32 \mathrm{Mbit} / \mathrm{s}(16 \mathrm{QAM}) \\
\text { Both way }\end{array}$ \\
\hline $\begin{array}{l}\text { Transmission } \\
\text { Power }\end{array}$ & $14 \mathrm{dBm}(\mathrm{QPSK}), 11.5 \mathrm{dBm}$ (16QAM) & $11.5 \mathrm{dBm}(16 \mathrm{QAM})$ \\
\hline Antenna & $\begin{array}{l}\text { AP: Omni, Sector(90degrees), Horn } \\
\text { WT: Plate }\end{array}$ & $\begin{array}{l}\text { WT-WT(19cm square) } \\
\text { (Gain: } 31.5 \mathrm{~dB} 1)\end{array}$ \\
\hline Interface & 100Base-Fx, 100Base-Tx & 100Base-Tx \\
\hline $\begin{array}{l}\text { Transmission } \\
\text { distance }\end{array}$ & $\begin{array}{l}\text { Approx. } 1.2 \mathrm{~km} \\
\text { (depends on the rain intensity) }\end{array}$ & $2 \mathrm{~km}$ (WT-WT) \\
\hline Number of WTs & Max. 239 WTs per AP & WT-WT pair \\
\hline
\end{tabular}




\subsection{Verification of operability}

(1) Voice over wireless LAN (Wi-Fi)

Unlike the traditional wireless LAN system specifically designed for data transmission, in order to enable the use of voice terminals, following points were taken into account in designing the system in this experiment. The operability was verified.

- To assure real-time voice communication, a dedicated for voice was set up, and access point was installed, separating voice and data.

- The number of terminals to be covered by one access point was limited to under 10 and fall-back was restricted to maximize the output.

- Each terminal is assigned fixed IP address, and handover between access points was realized with common-key encryption which has a short processing time.

(2) Verifying operation of WIPAS

A system was created which allow collection of climatic data, e.g. rainfall, temperature, wind velocity, as well as operational monitoring data such as number of packets transmitted and received, the level of received signal through VPN from Japan. Fig. 3 has sample number of packets transmitted and received. Teachers at the elementary school say the pupils are accessing the Internet a lot in the morning, and the traffic shown in Fig. 3 corresponds to this. 15 PC's at the elementary school were connected to WIPAS, but the peak for Fig. 3 is around 2,000 packets per every 10 seconds, which corresponds to 2.4Mbit/s (assuming the Ethernet Frame to be maximum 1500 Bytes). Fluctuation becomes large when counted on per a second basis, but WIPAS (P-P) has a capacity for 32 $\mathrm{Mbit} / \mathrm{s}$, so this range of traffic at the school should pose no problem.

The demonstration experiment was conducted during dry season, so there was no receiving signal error due to rainfall. WIPAS operated without any problems. Experiment with WIPAS in continuing, so as to verify its operation in rainy season. Rain rate measured by weather monitoring device installed in WIPAS, as well as sample error rate observed are shown in Fig. 4. Incoming signal level of $26 \mathrm{GHz}$ WIPAS is normally $-53 \mathrm{dBm}$ due to spatial propagation loss with $2.3 \mathrm{~km}$ propagation distance, but when it is raining heavily over $100 \mathrm{~mm} / \mathrm{hour}$, it goes below $-70 \mathrm{dBm}$ due to attenuation by rainfall. Incoming signal level below $-75 \mathrm{dBm}$ causes deterioration in receiving signal error ratio, connection is dropped, rendering it unusable. However, as shown in Fig. 4(a), the duration of time of more than $100 \mathrm{~mm} /$ hour rain is only a few minutes. This will hinder voice communication and web access that require real-time response, but sending/receiving mail is not damaged, as it allows for several minutes of delay. Continued observation is needed for calculation of more accurate unavailability ratio.

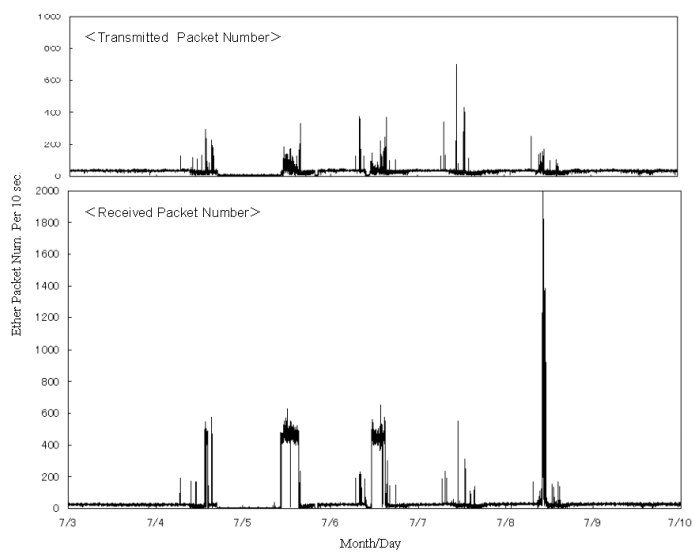

Figure 3 Ethernet packet count number per $10 \mathrm{sec}$.

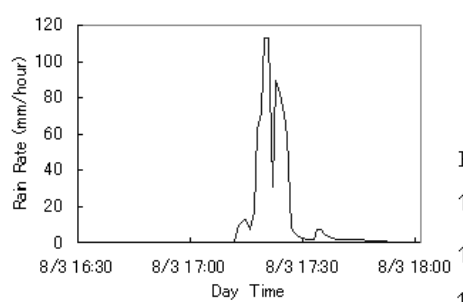

(a) Rain Rate

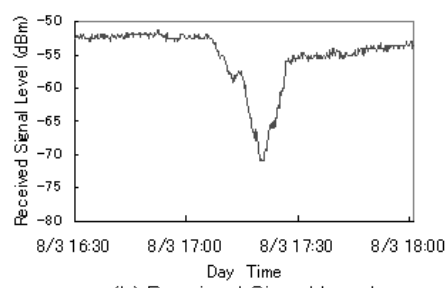

(b) Received Signal Level

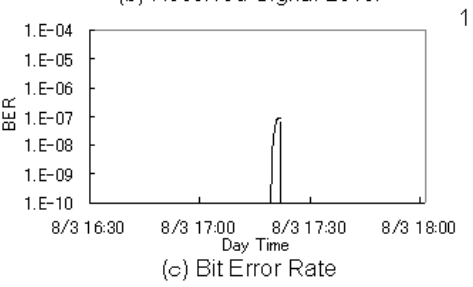

(c) Bit Error Rate

Figure 4 Rain rate, Signal level and BER

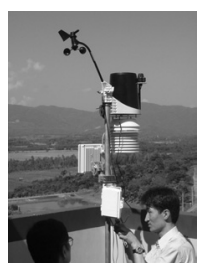

WT in MFLU

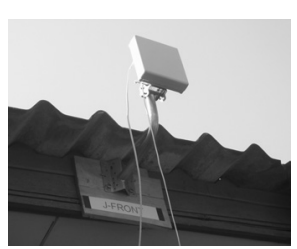

WT in the school

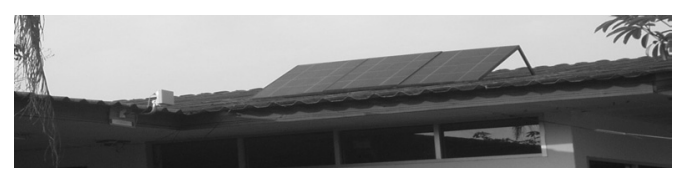

Solar panels in the school

Figure 5 Photographs of WIPAS、 and solar panel

(3) Independent power supply system

For the independent power supply indispensable in the Mekong region, where there are spots with no power, solar panel and lead-free, long-life and safe LiMn batteries are combined, and the following items, as well as compatibility with WIPAS was tested: 
- Solar panel generating capacity: 48V 2A(when sunny)

-Unit power output: $24 \mathrm{~V} 0.5 \mathrm{~A} 、 7.5 \mathrm{~V} 0.5 \mathrm{~A}$

- Operating time: Over 8 hours without sun

(Thai ENTEC solar panel used)

3.3 Evaluation of FWA

(1) Potentiality for area coverage

The configuration for demonstration experiment shown in Fig. 2 could simulate MFLU as center of a village, and the elementary school $2.3 \mathrm{~km}$ away as sub-village. In rural areas, usually optical fiber or metallic cable are installed in public buildings such as village administration building or schools located at the center of village. Connecting the center and sub-village with WIPAS is enabling wider coverage area. There are approximately 70,000 villages in Thailand, and their average land area is 7.7 square kilometers $\left(\sigma: 4.9 \mathrm{~km}^{2}\right)^{[10]}$. Since the operation of $2.3 \mathrm{~km}$-entrance circuit was verified, it means most of the villages can be included. With WIPAS, one can combine point-to-point and point-to-multi-point types, or connecting multiple point-to-point systems in tandem, extending relayed distances ${ }^{[11]}$, which makes it possible to cope with villages with different geographical shapes.

(2) Securing power source; ease of installation

Generally, power is more widely available than telephone. In Thailand, $97 \%$ of villages have power, and so do $65 \%$ of rural areas in Vietnam ${ }^{[12]}$. Commercial power supply is pre-requisite for location of Gateway (IP-PBX or mobile centrex), but location of WIPAS and Wi-Fi needs to anticipate the possibility of no power, these do not require high power like traditional telephone switching systems did. In places without power, solar power with simple solar panel or small, light-weight Manganese Lithium-ion type batteries such as the one used in the demonstration experiment may be used. For cellular terminals, portable solar power charger is commercially available.

Installation of the system including power supply is easy. In the experiment, once all the supplies were in order, one pair of WIPAS and $16 \mathrm{Wi}$-Fi access points were installed for two days.

(3) Remote maintenance capability

Since it is rural area, remote monitoring and control function is indispensable. In the demonstration, the local system was connected to Tokyo via Internet VPN, in order to collect data on operation and climate information, and to be able to cope with problems if they arise. When large-scale wireless LAN or FWA is implemented in rural areas and have them connected to public cellular and fixed networks, an integrated network management system will be needed. For this type of network management, a reference model shown in Fig. 6 is feasible. SNMP (Simple Network Management Protocol) may be applied to wireless LAN devices such as access points and WIPAS, thereby enabling build-up of a management system easily in a short period of time.

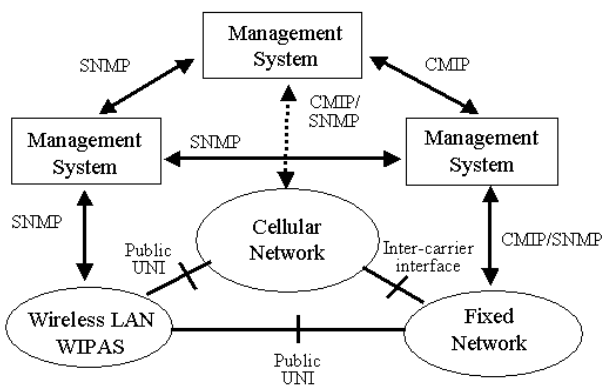

Figure 6 Reference model for network management

\section{Proposal for FWA and Cellular Connection by FMC}

In order to use the IP network realized with the afore-mentioned FWA for voice communication, and to communicate with parties outside of community, link to public telephone networks is indispensable. Response from the monitors in the experiment also indicated a strong desire to be connected to public cellular and fixed phones. Following is a proposal to realize such demand.

\subsection{Gateway with mobile centrex}

In the Mekong countries, IP telephones do not have dedicated numbers (e.g. "050" in Japan). Thus in order to implement IP telephone, a gateway as indicated in Fig. 7 is needed. This gateway's functions can be attained with mobile centrex which has VoIP, SIP and authentication server's functions. While this mobile centrex system is beginning to be introduced in large-scale enterprises in corporations in developed countries, it can also be applied in rural areas of developing countries. Many developing countries have regulated VoIP services, but there would be no problem if mobile centrex is installed in each message area so that it does not affect the existing tariff system. In addition, many mobile centrex's have a function which transfer incoming calls to a cellular number when called terminal is outside Wi-Fi coverage area. Mobility can be expanded by using dual terminals with Wi-Fi and cellular (WCDMA/GSM). The calls are automatically forwarded to cellular network even when outside its own Wi-Fi coverage area, which increases the level of convenience. This is all possible with existing technologies and products.

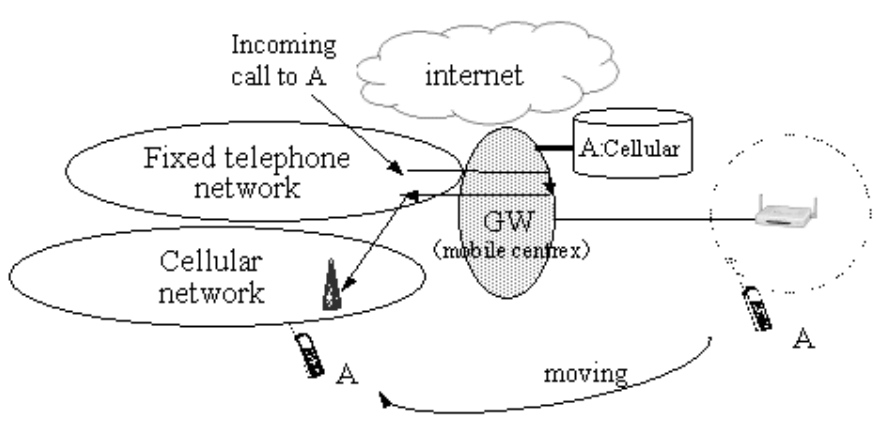

Figure 7 Connection by gateway with a mobile centrex 


\subsection{Integration of cellular and Wi-Fi networks}

Fig. 8 shows the method where wireless IP phone is assigned a cellular number, and when it is outside cellular coverage area, it is connected through fixed IP network. Within its own Wi-Fi coverage area, it is connected via wireless LAN. In cellular network, HLR (Home Location Register) keeps the area where each subscriber is located (the location area). When the subscriber moves and the area changes, the HLR is also updated to a new area code. As one of these location areas, "home Wi-Fi area " is added. With this system, when at home, connection via Wi-Fi is possible. Outside, it is connected via existing cellular network. When the terminal detects Wi-Fi radio signal over certain threshold, it notifies the cellular network through IP network that it is located in its own "home Wi-Fi area."

British Telecom's "BT Fusion" which was commercially launched this year, aiming at FMC seems to run on the same algorithm ${ }^{[13]}$. GW in Fig. 8 converts the telephone number to IP address, and connects to a designated access point. However, BT Fusion currently uses Bluetooth, rather than Wi-Fi, as UMA (Unlicensed Mobile Access Network).

However, since regional IP network is not built sufficiently in developing countries, they would use the public Internet in more cases. In this case, it may be difficult to assure QoS of voice communication. Network infrastructure to cope with demand for the Internet is needed. Also, BT Fusion had difficulty realizing seamless handover between Bluetooth and GSM, in rural areas where there is no cellular service available, handover function is meaningless and thus unnecessary.

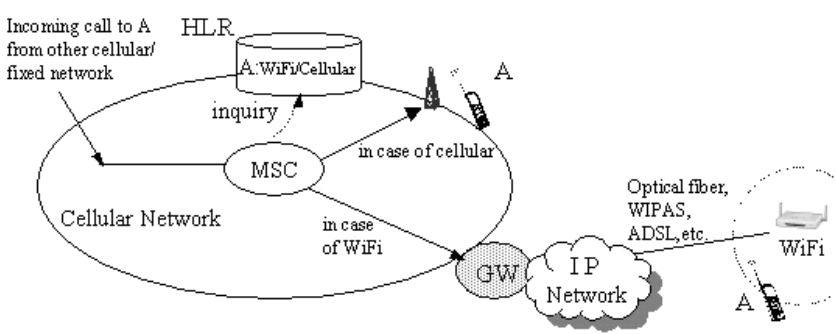

Figure 8 Integration of cellular network and Wi-Fi

\subsection{Evaluation of FMC}

4.1 and 4.2 methods are compared in Table 3. Applicability is reviewed based on this comparison.

Table 3 Comparison between gateway and integration methods

\begin{tabular}{|c|c|c|c|c|c|}
\hline Method & $\begin{array}{l}\text { Connection } \\
\text { with public } \\
\text { network }\end{array}$ & Terminals & $\begin{array}{l}\text { Mobility } \\
\text { of terminal }\end{array}$ & Dialing number & Remark \\
\hline $\begin{array}{l}\text { (Reference) } \\
\text { Fixed IP Phone }\end{array}$ & $\begin{array}{l}\text { VoIP GW } \\
\text { Gate keeper }\end{array}$ & $\begin{array}{l}\text { Fixed IP } \\
\text { telephone }\end{array}$ & \begin{tabular}{|l|} 
Length of IP \\
telephone cord
\end{tabular} & $\begin{array}{l}\text { Fixed telephone } \\
\text { number }\end{array}$ & - Already \\
\hline $\begin{array}{c}\text { Gateway with } \\
\text { mobile cetnrex } \\
\text { (Fig. } 7)\end{array}$ & $\begin{array}{c}\text { Mobile } \\
\text { Centrex } \\
\text { (forwarding } \\
\text { function) }\end{array}$ & $\begin{array}{l}\text { Wi-Fi/cellular } \\
\text { dual terminal }\end{array}$ & $\begin{array}{l}\text { Home Wi-Fi } \\
\text { area, } \\
\text { Cellular } \\
\text { coverage area }\end{array}$ & $\begin{array}{l}\text { Fixed telephone } \\
\text { number } \\
\text { Appearance: } \\
1 \text { terminal } 1 \text { number } \\
\text { Reality: } \\
1 \text { terminal } 2 \text { numbers }\end{array}$ & $\begin{array}{l}- \text { Possible with } \\
\text { existing system } \\
\text { - Connection } \\
\text { resource with } \\
\text { public networks } \\
\text { doubly used when } \\
\text { forwarding }\end{array}$ \\
\hline $\begin{array}{c}\text { Integration of } \\
\text { cellular and } \\
\text { WiFi } \\
\text { (Fig. 8) }\end{array}$ & $\begin{array}{l}\text { VoIP GW } \\
\text { Gate keeper }\end{array}$ & $\begin{array}{l}\text { Same as } \\
\text { above }\end{array}$ & $\begin{array}{l}\text { Same as } \\
\text { above }\end{array}$ & $\begin{array}{l}\text { Cellular number } \\
1 \text { terminal } \\
1 \text { number }\end{array}$ & $\begin{array}{l}\text { - Additional function } \\
\text { required in MSC, etc } \\
\text { - QoS an isse when } \\
\text { using Internet }\end{array}$ \\
\hline
\end{tabular}

\section{(1) Convenience of service}

Fixed IP telephony has no mobility, and it is simply a substitute for fixed telephone. This alone can provide telephone and internet, improving the level of convenience. When mobile centrex and Wi-Fi/cellular dual terminal are added, it would be possible to use it when moving within the Wi-Fi coverage area. The level of convenience is about the same as cordless phone. If the forwarding function of mobile centrex is used, it can be used outside Wi-Fi coverage area, gaining mobility equal to that of cellular phone.

\section{(2) Efficiency and rationality}

However, in the case of Fig. 7, if user leaves his/her own village often, forwarding occurs frequently. Needless to say, the capacity of interconnection between gateway and fixed telephone network is small in rural area. Going both direction with mobile centrex, it is inefficient since connection line resource is used twice. For better resource utilization, it makes more sense to include and manage the Wi-Fi coverage area (Fig. 8).

(3) Directory number and additional software function

It is more reasonable to assign a cellular number for telephone that provides mobility to the user. Cellular phones are becoming available in rural areas as well. It is desirable to use cellular number as connecting number in developing countries. In Fig. 8, if this becomes cellular coverage area, it can migrate with the same phone number.

(4) Feasibility for quick implementation

System outlined in Fig. 7 is possible with existing technology and products. Service can be provided with survey of existing telecom infrastructure in the area where this is to be introduced, design and installation of the system only. For those villages with urgent needs, this is appropriate. System in Fig. 8 requires additional software functions, but they are similar to those in BT Fusion.

\section{Possibilities for Applications}

In the demonstration experiment in northern Thailand, MFLU was connected via WIPAS with an elementary school nearby, and the broadband environment of the university was provided to this school. The school had been connecting 15 PC's to one telephone line, but through this experimental setup, they were able to provide more readily available IT education. In addition, e-learning library, real-time monitoring and video conferencing with web camera were provided. Cellular handsets with browser function is becoming available in the market, and once FMC is realized and services with mobility are provided, possibilities for applications are going to expand beyond education field.

If effective application development is carried out in the Mekong Basin, it can contribute towards the development of telecommunication infrastructure and industries, better 
government services, as well as protection of natural environment. Local products and tourist information can be put on the web and provided to urban areas, and purchase and request may be made online as well, using this for management of community or tourist businesses. Broadcasting from various databases must be feasible for community use in rural area. Also, they can develop a new system of predicting floods, observation of climatic conditions such as global warming. It could also be utilized as emergency communication channel at the time of natural disasters such as tsunami or typhoon.

With business models, applications and contents appropriate for the local communities, the value chain for information / telecommunication businesses ${ }^{[14]}$ will function better and develop even further.

\section{Conclusions}

We have made a proposal for a rural telecommunication system targeted at expansion of telecom infrastructure in rural areas of developing countries, utilizing cellular and fixed telephone, wireless LAN (IEEE 802.11b), and cellular/Wi-Fi dual terminals.

In the demonstration experiment, we verified the operation of mobile wireless IP telephony under the local environment. We also verified normal operation of WIPAS point-to-point with $2.3 \mathrm{~km}$. We collected rainy season squall data. Through these results we were able to obtain a good prospect for application of this FWA with combined Wi-Fi and WIPAS. We will still need continued measurement in order to obtain annual unavailability ratio. Also, we have to watch the development of WiMAX and compare it with this FWA.

In addition, we proposed two methods of FMC regarding interconnection between FWA and the public telephone networks. For those areas with urgent needs, the method of forwarding from WiFi to cellular network with the use of mobile centrex, already existing and readily available (Fig. 7) would be more appropriate. The integration method (Fig. 8) should also be implemented at the same time. With the integration method, one can use the same number when the cellular coverage becomes available in the area. These FMC methods are currently developed for corporate and urban users in developed countries, but we believe its true strength is brought out when implemented in the rural areas of developing countries, where there is no choice available for telecommunication services.

This proposal which combines FWA and FMC is a means that attempts to have the large-scale, nationwide cellular network and local, small-scale wireless LAN collaborate and fuse with each other, and it provides superior convenience. It is possible to implement in a short period of time, and it is provides the capability to cope with localities with no power supply, and remote maintenance. Furthermore, through using the Internet over this infrastructure, people will be able to develop various applications for tourism, environmental protection, education and government services that are needed in each local community. It is a system most appropriate for not only Mekong countries, but any rural area in developing countries. It is also more economically feasible for implementation than traditional rural telecommunication system $^{[15]}$, but this still requires further investigation for various cases of implementation.

If mobile wireless IP telephony combined with FMC which is being implemented in developed countries is applied to the rural areas, it could also serve to eradicate the digital divide.

Acknowledgement:

The demonstration experiment project conducted in Thailand in 2004 was made possible through funding from JETRO (Japan External Trade Organization). We would like to express our deep gratitude to those concerned in JETRO, MFLU and NECTEC, as well as to each member of this project.

\section{References}

[1] M. Matsumoto, K. Takeshita, Y. Yokoi, H. Ichikawa, A. Goto, "Development vision of IP Telephone applied to Mekong River region, Northern Thailand" in Proc. IEICE Gen. Conf. '05, B-5-152, March 2005.

[2] K. Takeshita, M. Matsumoto, Y. Yokoi, H. Ichikawa, A. Goto, "Field Evaluation of Wireless IP Telephone at Northern Thailand" in Proc. IEICE Gen. Conf. '05, B-5-153 March 2005.

[3] H. Ichikawa, M. Matsumoto, K. Takeshita, Y. Yokoi, A. Goto, "Field Evaluation of WIPAS at Mekong River region, Northern Thailand" in Proc. IEICE Gen. Conf. '05,B-5-154, March 2005.

[4] M. Matsumoto, H. Ichikawa, K. Takeshita, Y. Yokoi, A. Goto, "E-learning collaboration with MFLU Univ. and elementary school WIPAS broadband wireless network at Mekong River region, Northern Thailand" in Proc. IEICE Gen. Conf. '05, March B-5-155, 2005.

[5] Y. Hatakeyama "Networks; Mal-distributed to Ubiquitous" JSICR Journal vol.22 no.2, pp.63-72, 2004.

[6] T. Fujii, "Cellular Phone to Rural areas" ITU journal, vol.34 no.9 pp. 39-43, Sep.2004.

[7] K. Saga, "Problems and Prospects on ICT infrastructures in Asian Developing countries" Overseas Telecommunications Journal, vol.37 no.9, pp. 7-33, Jan.2005.

[8] K. Hiramatsu, "Wireless LAN+VoIP Rural Telephone System of Bhutan Telecom.” ITU journal, vol.35 no.1, pp. 3339, Jan. 2005.

[9] S. Kirachaiwanich, "The assessment of VoIP Call Quality for enhanced WLAN applied on RWBA" APT Seminar on ICT technology and Broadband Applications, Aug.2005.

[10] T. Koanantakool, P. Srisuksant, K. Wanichkorn, "Thailand Rural Wireless Broadband Access Initiative" NECTEC, Aug. 10, 2004.

[11] K. Nidaira, T, Shirouzu, M. Baba, K. Inoue, "Wireless IP Access System for Broadband Access Services" in Proc. ICC2004, vol.6, pp.3434-3438, June 2004.

[12] JTEC, "Study Report on Asia Broadband Initiative" http://www.jtec.or.jp.

[13] "FMC" Nikkei Communication no.437, pp.52-62, May 1. 2005.

[14] K. Wallets, M. Yoshida, "Beyond the Lean Communications Provider - Time to Create Sustainable Value" IEICE Transactions, vol.E82-B, no.11 pp. 1724-1728, 1999.

[15] JTEC, "Guide to Fixed Access systems for Rural Areas" http://www.jtec.or.jp. 